\title{
JOB DISPLACEMENT AND THE DURATION OF JOBLESSNESS: \\ THE ROLE OF SPATIAL MISMATCH
}

\author{
by \\ Fredrik Andersson * \\ Office of the Comptroller of the Currency \\ John C. Haltiwanger * \\ University of Maryland and U.S. Bureau of the Census \\ Mark J. Kutzbach * \\ U.S. Bureau of the Census \\ Henry O. Pollakowski * \\ Harvard University \\ and \\ Daniel H. Weinberg * \\ U.S. Bureau of the Census
}

CES 11-30

September, 2011

The research program of the Center for Economic Studies (CES) produces a wide range of economic analyses to improve the statistical programs of the U.S. Census Bureau. Many of these analyses take the form of CES research papers. The papers have not undergone the review accorded Census Bureau publications and no endorsement should be inferred. Any opinions and conclusions expressed herein are those of the author(s) and do not necessarily represent the views of the U.S. Census Bureau. All results have been reviewed to ensure that no confidential information is disclosed. Republication in whole or part must be cleared with the authors.

To obtain information about the series, see www.census.gov/ces or contact Cheryl Grim, Editor, Discussion Papers, U.S. Census Bureau, Center for Economic Studies 2K130B, 4600 Silver Hill Road, Washington, DC 20233, CES.Papers.List@census.gov. 


\begin{abstract}
This paper explores rich longitudinal data to gain a better understanding of the importance of spatial mismatch in lower-paid workers' job search. The data infrastructure at our disposal allows us to investigate the impact on a variety of job search-related outcomes of localized and individual-specific job accessibility measures using identification strategies that mitigate the impact of residential self-selection. Our results suggest that better access to jobs causes a statistically significant, but modest decrease in the duration of joblessness among lowerpaid displaced workers, while an abundance of competing searchers for those jobs increases duration modestly. Search durations for older workers, Hispanic workers, and those displaced from manufacturing jobs are especially sensitive to job accessibility.

* NOTE: An earlier version of this paper was prepared for the American Real Estate and Urban Economics Association meetings, January 2011. Any opinions and conclusions expressed herein are those of the authors and do not necessarily represent the views of the Office of the Comptroller of the Currency, the Department of Treasury or the U.S. Census Bureau. All results have been reviewed to ensure that no confidential information is disclosed. The authors want to thank Sheharyar Bokhari for his valuable research assistance, participants at various seminars and conferences for their suggestions, and Kevin McKinney and Ron Jarmin for their comments on an earlier draft. This research uses data from the Census Bureau's Longitudinal Employer Household Dynamics Program, which was partially supported by the following National Science Foundation Grants SES-9978093, SES-0339191 and ITR-0427889; National Institute on Aging Grant AG018854; and grants from the Alfred P. Sloan Foundation and the MacArthur Foundation.
\end{abstract}




\section{Introduction}

The purpose of this paper is to increase our understanding of the implications of spatial barriers to access to jobs, in particular lower-paid work, in U.S. metropolitan areas. The central assumption of the spatial mismatch literature that grew out of two papers by Kain $(1964,1968)$ is that accessibility to jobs is crucial for obtaining employment. The present analysis examines the importance and nature of this relationship using comprehensive, longitudinal employer-employee matched microdata developed at the Census Bureau. These confidential data enable us to construct measures of job accessibility that are person-based rather than general. In addition, with the longitudinal data we are able to focus on how the job search outcomes of displaced workers depend on the detailed spatial distribution of available jobs by industry and earnings. This approach, along with rich controls that longitudinal data permit, allow us to address selection issues to a much greater extent than the existing literature which mostly focuses on cross-sectional variation in the data.

As metropolitan areas expand and employment becomes more decentralized, many workers cannot live within a reasonable commuting distance of suburban jobs. This fragmenting of the labor market is exacerbated by zoning restrictions, possible discrimination in the housing market leading to racially segregated residential patterns, the historically bequeathed distribution of the housing stock and the public transportation network, and traffic congestion. These impediments also apply to knowledge of and search for jobs. As an example, following a separation in, say, manufacturing, finding employment in a different industry sector may be a searcher's best option, but each industry has its own unique spatial distribution of jobs, and each worker has different accessibility to those jobs. To the extent that re-employment requires job accessibility, viable public policy options could involve a variety of potential housing, transportation, and 
economic development policies, and this research aims to provide a more solid footing for such policy decisions.

The general presumption underlying the spatial mismatch literature is that high unemployment rates for some groups are at least partially a consequence of reduced job accessibility for workers in that group. However, since workers are not randomly distributed across space, it is difficult for cross-sectional studies to adequately address spatial "selfselection" inherent in the interactive residential and workplace location decisions of potential workers. Put differently, a key weakness of cross-sectional studies is that estimates may be contaminated because of failure to control for residence mobility in response to job accessibility. While the existence of this issue is hardly controversial, the degree to which it biases crosssectional outcomes is open to question. The current study provides a new approach to spatial mismatch by using rich longitudinal labor data for displaced workers. Estimates for this group should be less susceptible to this bias, since members of this group presumably did not become job searchers as a result of the current job accessibility. Furthermore, their pre-displacement residence choice should be less determined by current job accessibility. Our data permit analysis of how geographically-detailed, person-specific, and (in a future analysis) vacancy-based job accessibility measures affect job search outcomes including the duration of joblessness for displaced workers.

This research is made possible by the availability of a relatively new Census Bureau data source - the Longitudinal Employer-Household Dynamics (LEHD) dataset. ${ }^{1}$ These data provide detailed information on job location and residential location for workers in some states for all

\footnotetext{
${ }^{1}$ The micro data in the LEHD data infrastructure are confidential and protected by U.S.C. Title 13 and U.S.C. Title 26. External researchers may access the LEHD dataset for approved statistical purposes at one of the Census Bureau's Research Data Centers. See $<$ http://www.census.gov/ces $>$ for information on the application process. 2
} 
years back to 1990 (and in almost all states for fewer years). The LEHD data infrastructure is derived from integrated administrative and survey data and provides virtually universal coverage of workers covered by unemployment insurance (e.g., in a typical quarter, the LEHD data infrastructure is tracking more than 120 million workers and more than 7 million employers). These data allow the present analysis to examine the importance and nature of the relationship between accessibility and employment, and allow us to improve on the previous literature in four ways.

First, previous cross-sectional analyses could only examine whether those in more accessible locations had better employment outcomes, and were often unable to account for self-selection into those residential locations. Because our data consist of quarterly employment histories, we are able to focus on a narrow subset of individuals for whom the effect of accessibility should be most relevant, namely, on those who have just lost a job and are now seeking one. In addition, we are able to identify whether the job loss was likely to have been involuntary, allowing us to focus on the subset of job seekers who did not separate from their previous jobs as a result of the locally available job accessibility, which is a central argument for how we identify the effects of locally available job opportunities. Job displacement is defined here as a separation associated with an employer whose workforce shrinks more than 30 percent over a short period of time. Estimates of the impact of local job accessibility on job search-related outcomes for displaced workers should be less subject to reverse causality induced by local job accessibility also impacting the geographical distribution of job searchers. In addition, the longitudinal data permit us to control for earnings on the job prior to separation and thus control further for unobserved worker heterogeneity. 
Second, previous analyses often focused on a single dependent variable, such as wage level or the probability of being employed. We are able to measure a variety of search-related outcomes, including length of search, the quality of the new job relative to the previous job, relocations, and transitions between industries, though the analysis presented in this first paper focuses on just one, the duration of joblessness.

Third, previous analyses often had to use aggregate data covering broad geographic areas and labor markets to measure accessibility. Because much of our data is accurate to the detailed address level, we construct accessibility measures specific to each worker's home census tract and measure accessibility to a wide variety of job types. For example, we can construct industryspecific accessibility measures, or measure access to the locations of jobs for which workers were hired during that time period (as a proxy for the number of positions that may actually have been available at a given time). Furthermore, to reflect the topography and transportation network of an urban environment, we use peak-hour driving travel time as a measure of proximity. In a later version of this paper, we intend to also use travel time via public transit.

Fourth, our rich and comprehensive data on where people work and live permits us to explore an aspect of accessibility largely neglected in the literature. Specifically, it likely matters both how many jobs are close by (in terms of time) but also how many other potential workers are within reach of those firms that are accessible to the worker in question. We develop measures of “competing searchers" comparable to our job accessibility measures. ${ }^{2}$ Exploring both of these measures in an integrated manner is one of the contributions of our approach.

\footnotetext{
${ }^{2}$ See Raphael (1998) for an example of including competing searchers in a gravity model.
} 
In this paper, models are estimated using pooled data for six Midwestern metropolitan areas in multiple states that have their own point-to-point travel time data. The study areas vary in size, in abundance of employment sub-centers, and in diversity of industry sectors. In future work, we plan to expand on the number of metropolitan areas in our study using (1) data from other Metropolitan Planning Organizations on commuting times, and (2) the U.S. Department of Transportation's Census Transportation Planning Package data derived from Census 2000 long form data.

\section{Background Literature}

"Spatial mismatch" was first observed as a breakdown of the standard urban land use model. Observing 1950s data, Kain $(1964,1968)$ found that the location of jobs for Blacks was a poor predictor of their residences. This finding was observed to be consistent with racial discrimination in the suburban housing market, as an increasing number of jobs were moving to suburban locations. The inference made was that a high unemployment rate among central city Blacks was at least partially a consequence of inaccessibility to jobs. Presumably, distant jobs were more difficult to obtain due to high costs of search and commuting.

Kain's work positing a "spatial mismatch" between inner-city minority workers and suburban jobs has spawned a huge subsequent empirical literature, summarized by Kain (1992), Ihlanfelt and Sjoquist (1998), and Gobillon et al. (2007). Although the synthesis articles have been critical of much work, there is considerable evidence that job accessibility is partially responsible for poor labor market outcomes for inner city, low-skilled ethnic minorities. There is considerable disagreement about the magnitude of the spatial mismatch effect and over which 
groups of workers are most affected by it (Ihlanfeldt 2006). ${ }^{3}$ In this paper, we argue that much of the disagreement stems from deficiencies of the underlying data. We provide results based on much more detailed and comprehensive data, and also use longitudinal data to deal with inherent identification issues.

More recently, theoretical modeling has attempted to derive the spatial mismatch hypothesis from commuting costs and the job search process (for example, Arnott 1998, Brueckner and Zenou 2003, and Zenou 2009). Gobillon et al. (2007) provide a detailed discussion of the mechanisms of spatial mismatch. They posited that the mechanisms have remained unclear and thus not properly tested. They reviewed theoretical models, compared their predictions to empirical results, and suggested mechanisms deserving further testing.

A number of other recent studies that are relevant to our work are discussed below. These include Holzer et al. (2003), which focused on a public transit natural experiment; Raphael (1998), which focused on information disadvantages and competing searchers; O'Regan and Quigley (1996a, 1996b), which presented tests for omitted variable bias; Holzer et al. (1994), which dealt with search and commute lengths; Raphael and Stoll (2001), which dealt with the role of auto ownership; and Hellerstein et al. (2008), which focused on "racial mismatch."

Returning to the specific issue of minority discrimination, two potential types of discrimination can be distinguished: suburban housing discrimination and labor market discrimination. We first address housing location. The core of Kain's original argument was that racial discrimination in housing prevented Blacks from moving closer to jobs in the suburbs,

\footnotetext{
${ }^{3}$ The spatial mismatch principle has been applied to explain unemployment among other spatially concentrated groups. Examples are young people being tied to parents (Ellwood 1986; Ihlanfeldt and Sjoquist 1990) and refugees settled randomly (Aslund et al. 2010). Ihlanfeldt (1993) and Raphael and Stoll (2002) find smaller effects for other minority groups (Hispanics, Asians).
} 
driving up their unemployment rate (and also their rents). By limiting their choice of

employment location, this process would also drive down the average wage for inner-city Blacks

(Kain 1964). Of course, evidence of decreasing residential segregation for Blacks would be expected to reduce such effects of spatial mismatch, but the 2000 level of Black residential segregation remains the highest of any minority group (Iceland and Weinberg 2002). If spatial mismatch has an effect, reductions of employment and earnings for minorities subject to housing market segregation ought to be present in recent data, although it is by no means clear a priori if these effects, if found, will be due solely to housing market discrimination, as labor market discrimination or information inequality can also play a role.

Browne et al. (2001) argued that the lower wages received by Blacks are the result of lower skills, not of housing market discrimination, at least in the Atlanta metropolitan area. Houston (2005) argued that skills mismatch and spatial mismatch are intertwined and reinforcing. Houston also took note of the potential importance of spatial experiments. ${ }^{4}$

As noted by Perle et al. (2002) and others, job access should ideally be defined as access for a jobless worker to job openings that match his or her skill level. Because of data deficiencies, few if any studies are able to account for job vacancies per se. Houston (2005) noted that "The use of jobs as a proxy for vacancies in accessibility measures causes a bias..." because the stock of jobs is not necessarily a good proxy for new jobs. Houston also noted that the "friction of

\footnotetext{
${ }^{4}$ On spatial experiments, Houston notes: "Certain changes in urban structure constitute a change in the spatial relationship between home and workplace while nothing else changes, and these changes can be regarded as naturally occurring spatial experiments. ...These spatial experiments focus on a fixed set of particular individuals and follow their responses through time to a spatial change in the relationship between home and workplace." Naturally occurring spatial experiments that can provide data to test the hypotheses include transport improvements, such as a new highway, river crossing, or rail line; forced housing relocations, such as demolition associated with government redevelopment programs; and firm relocations within a metropolitan area. 
distance" is important, especially the characteristics of transportation networks. ${ }^{5} \mathrm{He}$ also noted that the effects of job accessibility can also be affected by locational characteristics - both within a metropolitan area and across metropolitan areas:

Our research is intended to address several of the important issues raised by Houston. For example, our research addresses the 'friction of distance' issue by using census tract-to-tract measures of auto and public transit morning peak commute times produced by metropolitan planning organizations (MPOs). A longer-term goal of our research is to compare the role of spatial mismatch across a number of types of metropolitan areas (six are included in this study). Our data infrastructure also permit measuring job accessibility in a number of ways - in the current paper, we focus on accessibility of existing jobs but plan in future versions to explore accessibility based on new hires (which is more closely tied to vacancies).

O'Regan and Quigley's model of youth employment (O'Regan and Quigley 1996a, 1996b) dealt with a number of problems in the literature. Because of the potential endogeneity of youths' work and school decisions, they specified a model of youth idleness (not at school or work) in which the probability of not being at school or work is a function of a vector of individual and family characteristics expected to affect behavior, a vector of neighborhood characteristics, a measure of job accessibility, and a vector of metropolitan area characteristics. Their individual and family characteristics included sex, age, education, whether in a household with a nonmarried female householder, householder's education, whether a parent is employed, whether the youth is in school, family size, household income other than the youth's, and whether the female youth is a parent. As neighborhood characteristics, O'Regan and Quigley used percent White;

\footnotetext{
${ }^{5}$ The use of average commuting time in spatial mismatch models can introduce selection bias as those times relate to the behavior of the employed, and the hypothesis concerns the unemployed; see Houston 2005. 
percent of households receiving public assistance; percent below poverty level; percent unemployed; and percent of adults 25-64 not at work; some of these are used to test for omitted variable bias.

As Glaeser (1996) and others have pointed out, omitted person characteristics are highly correlated with neighborhood choice and the latter is endogenously chosen. This will bias estimates that rely on neighborhood-specific effects. A possible response to this criticism is to limit analysis to youths living with a parent or grandparent and assuming that it is the availability of jobs to the householder that determines residential location (i.e., that parents do not typically choose their residential locations based on job opportunities available to their children). Glaeser (1996) nonetheless argued that bias can remain, and suggests that one "could separate individuals into long-term and short-term residents of the community."

Raphael (1998) explored the roles of information disadvantages and competing searchers. He controlled for the intervening opportunities and intervening labor supply for origin-destination pairs. This decreases the negative effect of distance on the labor flow between zones by almost 90 percent. He noted, nonetheless, that "physical distance has a significant and substantial negative effect on intra-metropolitan (male teenage) youth labor flows. Despite the high correlation between intervening opportunities and intervening competing workers, both spatial variables have sizable, and independent, effects on labor flows."

Holzer et al. (1994) focused on inner-city Blacks searching for work and commuting to work in outlying areas. ${ }^{6}$ They found that (1) Blacks and inner-city residents have longer commutes, but cover somewhat less distance while searching and commuting (and that this higher time cost is

\footnotetext{
${ }^{6}$ They note that Zax and Kain's working paper (later published as Zax and Kain, 1996) shows that the relocation of large firms out of central-city areas increases commute times for their Black employees and raises their quits as well. 9
} 
partially accounted for by lower automobile ownership), (2) greater degrees of job decentralization across metropolitan areas do not result in longer commutes among Blacks and central-city residents, and (3) automobile ownership has negative effects of duration of joblessness. They concluded that "given the relatively small gains from non-auto travel, the search and commute choices of inner-city Blacks may be quite rational ... [and that] it also seems unlikely that efforts to remove transportation barriers alone (such as public transportation programs) will fully resolve the spatial mismatch problem."

Holzer et al. (2003) made use of a natural experiment to look at the spatial distribution of minority employment. An expansion of the San Francisco Bay Area Rapid Transit (BART) system provided the authors with "an exogenous change in accessibility of inner-city minority communities to a concentrated suburban employment center." They found a substantial increase in the hiring of Latinos by employers near the new stations, but little evidence on the hiring of Blacks. They cited numerous studies linking poor households and public transit. For example, they noted that poor households disproportionately live in locations accessible to public transit, and that this pattern is consistent with considerable dependence on public transit. As motivation for turning to a natural experiment, they acknowledged that "drawing causal inferences (from transportation studies) requires making strong identifying assumptions." For example, firms employing large numbers of low-skilled and transit-dependent workers may locate near transit stops, while firms wishing to discourage minority workers may locate farther from such stops. They concluded "No labor market studies have resolved this issue satisfactorily. Indeed, no study has identified a clear source of exogenous variation in spatial access to employment opportunities." 
Raphael and Stoll (2001) approached spatial mismatch by asking if increasing minority auto ownership rates can narrow inter-racial employment gaps. Making a comparison across metropolitan areas, they found that having access to a car is particularly important for Blacks and Latinos, and that the difference in employment rates between car-owners and non-carowners that is greater among Blacks than among Whites. They also found that the difference between Blacks and Whites in their car-employment effect is the largest in metropolitan areas "where the relative isolation of Blacks is most severe."

As noted above, we depart from much of the existing work on spatial mismatch that focuses on cross-sectional variation to an approach that relies heavily on following workers who have experienced a job displacement. There is a substantial literature in labor economics studying the impact of job displacement following the seminal paper of Jacobson et al. (1993). ${ }^{7}$ Using matched employer-employee data for the state of Pennsylvania, Jacobson et al. showed that workers separating from a sharply contracting employer experience a substantial and persistent loss in earnings. Subsequent research (e.g., Dardia and Schoeni 1996) showed that the substantial and persistent loss of earnings is especially pronounced for those workers who also experience substantial (and in many cases repeated) spells of joblessness following the displacement.

A closely related literature has shown that separations from a sharply contracting business are more likely to be associated with a layoff (an involuntary separation) as opposed to a quit (see Davis et al. 2010 for a summary of this literature). Moreover, the literature shows that workers who experience a layoff are much more likely to experience a spell of unemployment than those who separate due to a quit (see, Elsby et al. 2010).

\footnotetext{
${ }^{7}$ Other papers on job displacement using LEHD data include Lengermann and Vilhuber (2002) and McKinney and Vilhuber (2006). 
In sum, our research deals with Glaeser's (1966) self-selection issue by examining duration of joblessness by displaced workers. Our measure of accessibility takes into consideration all relevant jobs, but discounts them by a function of commute times, and takes account of competing searchers (cf. Raphael 1998). While the current version of our research considers accessibility via autos; future work will consider accessibility via public transit, and accessibility to vacancies rather than to all jobs. We note, however, that the contribution of public transit to job accessibility of workers residing in the inner city is likely to be small relative to auto accessibility. This is in large part due to the high commute times involved.

\section{Methodology}

As mentioned above, a central assumption of the spatial mismatch literature is that accessibility to jobs plays a role in obtaining employment. We contribute to the literature by characterizing the challenge of spatial mismatch as a job search impediment, by addressing the endogeneity of a sample of job searchers, and by assembling geographically granular measures of accessibility, specific to groups of searchers. In this section we discuss each of these key contributions as we motivate the stochastic specification that is then analyzed empirically. As we have not yet implemented all the contributions that our data permit, in the discussion we also make clear the more limited scope of the empirical analysis presented in this version of the paper.

\subsection{Capabilities of employer-employee matched data}

Previous work on spatial mismatch has been handicapped by the limitations of crosssectional data and a lack of precision in measuring the spatial distribution of job opportunities. 
Use of the Census Bureau's Longitudinal-Employer Household Dynamics (LEHD) data, an employer-employee matched database composed of state administrative records data and internal Census data, permits us to proceed at a detailed level of geography for most U.S. workers. An extensive description of the LEHD Program at the Census Bureau can be found in Abowd et al. (2004). LEHD data permits us to follow workers over time (Andersson et al. 2004). ${ }^{8}$ At its core are two administrative records files provided by states to the Census Bureau on a quarterly basis: (1) unemployment insurance (UI) wage records, giving the earnings of each worker at each employer, and (2) employer reports giving establishment-level data, also known as the Quarterly Census of Employment and Wages (QCEW), but often referred to as the 'ES-202' program. The coverage is roughly 96 percent of private non-farm wage and salary employment. ${ }^{9}$

The LEHD database infrastructure permits tracking all worker and job flows - i.e., all accessions and separations at the person and employer level as well as employer-level information on job creation and destruction. For our purposes, the complete work histories enable one to compute labor market outcome measures over any given period such as the cumulative number of jobs, the number of spells of joblessness, the durations of spells of joblessness, and the earnings levels and growth within and between jobs. The national nature of the files enable one to track workers who relocate geographically as they move from one job to another (including tracking any spell of joblessness involving this transition).

\footnotetext{
${ }^{8}$ The Local Employment Dynamics partnership between the Census Bureau and all 50 states and D.C. produces jobs data that are widely used by state and local governments. All 50 states have now agreed to become part of the program but not all states' data are as yet fully incorporated into the infrastructure in terms of data availability and production of LEHD core products (Quarterly Workforce Indicators and On-the-Map commuting patterns).

${ }^{9}$ There are plans underway to include the self-employed and federal workers from other administrative records sources but we did not yet have access to those improved data for the current analysis. The coverage of agricultural employment is less comprehensive. 
This study integrates the LEHD infrastructure files with confidential household data from the 2000 Census, which provides household and individual responses on housing and person characteristics, with detailed place of residence information from federal administrative data, and with vehicle travel time data for the metropolitan areas included in this study. Research at the Census Bureau has found good match rates between the 2000 Census long form and LEHD wage records. ${ }^{10}$

\subsection{Stochastic Specification}

We model the outcomes of the job search process for a worker, $i$, based on versions of the following generalized linear model specification:

$$
y_{i}=\Lambda\left(\boldsymbol{\beta}^{\prime} \mathbf{A}_{\mathrm{j}(\mathrm{i})}+\boldsymbol{\gamma}^{\prime} \mathbf{x}_{\mathrm{i}}\right)
$$

where $y_{i}$ is one of the dependent variables reflecting some outcome of the job search process; $\mathbf{A}_{\mathrm{j}(\mathrm{i})}$ is a vector of measures of accessibility to jobs of different skill types (defined by industry or earning ranges of jobs or perhaps education level) or, in its most simple form, a singledimensioned job accessibility measure from the census tract $j$ in which individual $i$ resides; and $\mathbf{x}_{\mathbf{i}}$ is a vector of other controls associated with the individual. We discuss the details of the job accessibility measures and other key control variables below. By imposing the relevant link function $\Lambda$ associated with the outcome of interest, we can then estimate the parameters of interest, $\boldsymbol{\beta}$ and $\gamma$.

For this analysis we use a logistic function and specify an ordered logistic model, where the duration of joblessness (or job search length) after a job displacement event serves as the

\footnotetext{
${ }^{10}$ See Andersson et al. (2010). 14
} 
dependent variable. With LEHD earnings data, we measure duration in terms of quarters (3month periods), an ordered discrete variable. A key advantage of our data as compared to data used for most previous analyses is that it permits analysis of longitudinal outcomes, such as wages, employment status, and quality of the new job relative to the previous job, relocations, and transitions between industries. Future analyses will make use of other econometric models, depending on what the exact outcome is that is examined.

We estimate our model using pooled data for all displaced separators (as defined below) as well for subpopulations of workers, defined by gender, race and ethnicity, and age to test if different groups of workers are differentially affected by local job accessibility. We also examine subpopulations of job searchers defined by the industry which they were separated from, and with job accessibility measures specific to that industry. In future work we will also separately examine, or control for, various household characteristics, such as vehicle ownership, primary earner status in the household, and homeownership status.

\subsection{Identification strategy}

The spatial mismatch hypothesis implies that local job opportunities have a strong impact on lower-paid workers' outcomes in the job search process. Workers in job-scarce areas may face a more challenging job search requiring long and costly commutes into less-familiar locations. One consequence of spatial mismatch, which has been widely studied, is that potential workers in job-scarce areas may have worse labor market outcomes, often measured as a higher unemployment rate. An econometric challenge for research on spatial mismatch is that local job accessibility also impacts the geographical distribution and sorting of populations of job searchers. In cross-sectional data this type of reverse causality translates into a positive 
correlation between local job accessibility and labor market outcomes and makes it very difficult to disentangle the exogenous impact of local job accessibility in the job search process. ${ }^{11}$

In contrast, we identify the causal effect of local job accessibility in the job search process by explicitly attempting to restrict the population of job searchers to those that could not have become job searchers as a result of the locally available job opportunities. In particular, following Jacobsen et al. (1993), we identify workers who became separated from their previous employer during a firm displacement event. Estimates of the impact of local job accessibility on job search-related outcomes for displaced workers should be less subject to reverse causality induced by local job opportunities also impacting the local pool of job seekers.

Even so, our approach does not guarantee that causal effects of job accessibility can be identified. In particular, to the extent individuals self-select into areas and given some degree of persistence in local job accessibility over time, it is quite conceivable that the effects of initial self-selection persist also at time of displacement. While controlling for a wide range of productivity-related individual characteristics, such as education and experience, should alleviate the impact of self-selection on job accessibility estimates, the scope for success is limited if selfselection is based also on unobservable characteristics. For instance, it is easy to imagine that more motivated and career-driven individuals (traits that are difficult to measure) have a higher propensity to move to where the jobs are. For this reason we also include total earnings from all employment in the year prior to the separation as a control in all our specifications. Annual

\footnotetext{
${ }^{11}$ Note that a standard job search models (e.g., Burdett and Mortensen 1998) imply that the bias in cross-sectional data would remain even if workers are homogenous, as long as there is a distribution of wage offers. This is an interesting observation given that the previous literature has been focused on attempting to address biases associated with residential self-selection based on observable and unobservable worker characteristics, which would not account for the bias induced by that the local wage offer distribution also impacting the share of voluntary separations (separations associated with higher wages and shorter durations of joblessness as compared to involuntary separations).

16
} 
earnings from the job lost due to displacement is a broad measure of observed and unobserved productive traits of the worker, and captures the effects of initial self-selection into neighborhoods. ${ }^{12}$ We control for a host of other demographic, household, and employment history characteristics, as well as year and quarter effects, and fixed effects for the metropolitan area of residence. $^{13}$

\subsection{Measuring Job Accessibility}

Most previous analyses had to rely on aggregate data covering broad geographic areas and labor markets to measure job accessibility. Such measures fail to pick up the variation in job accessibility, so estimates of the impact of job accessibility are subject to potential problems of measurement error bias. Furthermore, at least implicitly, most previous studies assume that the impact of accessibility does not vary with respect to type of jobs. Evidence of large differences in the spatial distribution of jobs across industry and other job traits along with the importance of job-specific human capital suggest that this is another potentially important source of measurement error bias that could attenuate coefficients. For instance, the impact of job accessibility on job-search related outcomes of a laid-off manufacturing worker is likely to be larger if the locally available jobs are primarily in the manufacturing sector than, say, in the financial services industry. Another implicit assumption in most previous studies is that

\footnotetext{
${ }^{12}$ Other strategies employed in the literature include instrumental variable analysis and restricting the sample to individuals whose initial location decision is arguably exogenous. An example of the latter is to restrict the analysis to young people residing with their parents. A potential drawback of that approach, in addition to potential problems of generalizing results to the broader population of interest, is that that approach does not control for self-selection based on unobservable characteristics shared among family members. In the context of our analysis an interesting alternative is to model job-search related outcomes as a function of the difference in job accessibility between time of displacement and an earlier period. Arguably the change should be exogenous to the residential location decision and make this potentially useful source of variation.

${ }^{13}$ We include metropolitan area fixed effects in our specification, but cannot report them because of agreements with the state partners. 
accessibility to existing jobs can adequately approximate job vacancies. While employment and vacancies are typically strongly correlated, that is not always the case, especially at the micro level.

Conceptually, we seek to develop job accessibility measures that can capture different patterns of job accessibility across cities. Figure 1 presents two hypothetical qualitative spatial forms that an urban area could take, as represented by job density, or accessibility. Figure 1A presents a schematic for highly monocentric metropolitan area; it consists of roughly concentric circles, with the highest accessibility in the darkest center area, with some variation based on the highway and public transit network. In Figure 1B, modest suburban employment subcenters are added; while residential locations close to these subcenters have some accessibility advantage, access is still not as high as in the center. A job accessibility measure should be able to capture the variation depicted in Figure 1. ${ }^{14}$

Our data permit the construction of job accessibility measures that (1) capture differences in job accessibility across very granular geographical areas; (2) are potentially industry- or skillspecific, and can potentially measure hiring opportunities; and (3) are based on travel times. In particular, we measure accessibility as the number of jobs of a particular earnings range located within a given drive time of a job searcher's home census tract. More formally, accessibility in census tract $j$ to jobs in industry, skill, or earning type $l$, denoted as $A_{j l}$, is calculated as

$$
A_{j l}=\sum_{k=1}^{K} H_{k l}
$$

where $H_{k l}$ proxies for the number of job opportunities in industry, skill, or earning type $l$ in census tract $k$, and where $k=1$ to $K$ is the set of census tracts within a given travel time range

\footnotetext{
${ }^{14}$ Due to agreements with state partners, we are not able to produce a map of job accessibility in any of the metro areas included in our sample at this time. 
from tract $i$, including $k=i$. The importance of jobs may vary with the proximity of those jobs to a worker's home; however, assigning importance to jobs of a given proximity is not straightforward. ${ }^{15}$ For the present version of this analysis, we assign a weight of 1 to all qualified jobs within 20 minutes drive time, and a weight of 0 for all other jobs. According to the American Community Survey estimates for 2005 to 2009, average commute time was about 25 minutes, and for larger urban areas, was typically above 30 minutes. Thus, our measure does not capture all jobs that a searcher might seek out, but indicates the abundance of nearby jobs. We have checked that our results are robust to using other travel time thresholds as well, including 30 minutes and 40 minutes. We include metropolitan area fixed effects to account for overall hiring conditions throughout a job market. Lastly, we take logs of all the spatial mismatch variables since we think it is reasonable to specify that the outcomes are a function of the percentage changes in the accessibility measures.

The job accessibility measure used in the present analysis incorporates some, but not all of these improvements. In particular, these results use measures of job accessibility based on total employment in lower-wage jobs, at the census tract level. As is assumed in many previous studies of spatial mismatch, the distribution of jobs is likely to be closely associated with the distribution of job openings (we also plan to study the distribution of job openings in future work). We obtain total employment, by census tract, from a publicly available product provided by LEHD, known as OnTheMap (OTM). The OTM project has created census block-level place of work, place of residence, and journey-to-work job flow data from 2002 to 2009 for all states in the Local Employment Dynamics (LED) Federal-State Partnership. OTM also provides job

\footnotetext{
${ }^{15}$ For example, a gravity-based job accessibility index might discount the importance of jobs by the inverse of a proximity measure to some power. With a power of 2 , a job that is 20 minutes away might be discounted by a factor of 400. Because such discount factors are typically arbitrary, we will examine them further in future work. 19
} 
counts by industry, which we use in an industry sector-specific measure of job accessibility. ${ }^{16}$ Specifically, we use the number of private sector jobs earning less than $\$ 40,000$ held as the highest earning job for each worker (also known as a primary job in OTM) in 2005. We restrict the analysis to private-sector jobs to avoid differences in how states report public-sector jobs. To best reflect the opportunities available to low-wage workers, we do not include higher-earning jobs. Because the displaced worker sample will include only those workers losing their highestearning job, we also restrict the measure to include only primary jobs (the highest-earning job at that time, of each worker in the LEHD database). Primary, or dominant, jobs are likely to be the most comparable replacements for the dominant jobs that displaced workers have just lost. In the future, we plan construct more contemporaneous measures directly from LEHD infrastructure data, such as the number of new hires or jobs created by new employers.

We use automobile travel time to define the set of jobs in the vicinity of a job seeker. Travel times are based on auto travel network modeling results obtained from a Metropolitan Planning Organization (MPO) in each of the study areas, which are located in the upper Midwest. ${ }^{17}$ MPOs in major U.S. metropolitan areas use network modeling techniques to estimate auto and public transit commute times, for the morning peak period, among all combinations of Traffic Analysis Zones (TAZs). For this study, these TAZ-to-TAZ results are translated into tract-to-tract measures. One advantage of using travel time estimates is that they are directional. For example,

\footnotetext{
${ }^{16}$ Using OTM data has some advantages over using the LEHD infrastructure directly to measure job abundance. Although some employers report their location accurately to the census block level, OTM supplements other imputation methods in the LEHD Employer Characteristics File and imputes a census block for all jobs. In addition, OTM produces synthetic place of residence data at the census block level. Thus, even though the OTM data are highly detailed, and are an accurate representation of the overall pattern of job density by place of work and worker density by place of residence, employer and individual confidentiality are protected.

${ }^{17}$ Because of disclosure concerns and the agreements with the individual states in the LED Partnership, we are unable at this time to identify the specific metropolitan areas or states studied.
} 
a morning commute inbound toward the Central Business District may take longer than the same morning reverse commute, due to traffic congestion. ${ }^{18}$ Given the importance of public transit to low-earning workers, public transportation networks and vehicle ownership will be added to the analysis in future drafts. ${ }^{19}$ However, based on MPO transit data obtained to date, we note that the contribution of public transit to job accessibility of workers residing in the inner city is small relative to auto accessibility (provided that they have access to a car). This is in large part due to the high commute times involved and the limited extent of transit networks. Alternative travel time measures based on the 2000 Census Transportation Planning Package (CTPP), which has a national scope, are being explored. A disadvantage of the CTPP is that it only includes reported commutes, and is thus a sparse matrix of travel times.

No matter how accessible jobs are in an absolute sense, the success of a worker will depend in part on the presence of competitors in the labor market. It can be argued that the greater the number of workers who reside nearby, the longer the period of joblessness is likely to be. However, a larger numbers of nearby workers means that local workers might have better information sources about vacancies. For example, if social networks are important for finding jobs then having lots of workers as neighbors might help in finding jobs. To control for the localized effects of labor supply (the competing searchers hypothesis mentioned above), without conflating labor supply with neighborhood effects, we calculate the weighted average of the total number of workers that could potentially be competitors for a job opportunity. Like the measure of job accessibility, this measure uses OTM jobs data, but rather than measuring where jobs are,

\footnotetext{
${ }^{18}$ In fact, as the quantity of suburban jobs has grown, "outbound" commute times towards the suburbs are now sometimes greater than "inbound" times going the opposite direction on the same route.

${ }^{19}$ Nationally, there are about 40 metropolitan areas where MPOs could provide auto commute times, and in some cases, transit times as well. 
it measures where workers live (and includes all private sector, primary jobs, even though those job holders may not be actively searching for a job). Just as before we assumed that the workplace distribution of jobs is associated with the distribution of job opportunities, here, we assume that the residential distribution of current job holders is associated with the distribution of those potentially seeking jobs.

We calculate the number of competing searchers using an analog of the job accessibility measure, $A_{j l}$, used above. However, instead of using the number of competing searchers living within 20 minutes of the job searcher, we use a weighted average of the number of competing searchers that could potentially reach each job within a comparable or faster travel time as the job searcher. Consider a measure of competing searchers, $S_{j l}$, for jobs of earnings range $l$ and with workplaces within 20 minutes of census tract $j$, located in tracts $k=1$ to $K$. For each of these tracts $k$, we calculate the number of workers, $W_{k l}$, who could travel to it from their residences in 20 minutes or less. We then calculate the average number of workers that can travel to tracts $k=$ 1 to $K$ in less than 20 minutes, weighting by the number of jobs located in each tract $k$, or $H_{k l}$. The weighting is crucial because it emphasizes the competition faced in job-rich tracts, and discounts competition faced in job-scarce tracts. Specifically, we use the formula:

$$
S_{j l}=\frac{1}{A_{j l}} \sum_{k=1}^{K} W_{k l} H_{k l}
$$

where, as explained above, $A_{j l}$ is the sum of jobs within 20 minutes of tract $j$. Measuring competing searchers in this manner recognizes that labor supply may come from parts of a city other than where a job searcher lives. For example, a job seeker living in the inner city may be competing for suburban jobs with searchers living in the suburbs, and those competing searchers may live even closer to the job opportunities and may be better informed about job openings. 


\section{Sample Description and Variable Construction}

To generate a sample of job searchers, we begin by defining a set of separated workers with demonstrated labor market attachment. We draw earnings histories from the LEHD Employment History File (EHF) for states including metropolitan areas covered by this study. The EHF tracks quarterly earnings (but not hours) of each worker for jobs covered under state unemployment insurance systems. A separation is defined as the termination of wages paid to a worker, with no resumption of wages from that same employer for at least 1 year. ${ }^{20}$ We restrict the sample by requiring that separators earned wages from an employer in each of the 4 quarters prior to the last quarter in which they received wages. This tenure restriction is meant to limit the sample to separators that had established ties to their employer and attachment to the labor market. Such workers may be more likely to engage in a search for a new job. ${ }^{21}$ This study includes separators who last earned wages in the years 2000 to 2005 , or in terms of quarters, 2000:1 to 2005:4.

From the EHF, we also construct a set of control variables and sample restrictions that are likely to be related to job search outcomes. For the 4 quarters prior to the quarter of separation, we calculate total earnings from the separated job, as well as total earnings from all other jobs. As we discuss below, we also construct a measure of total household earnings. While these alternative earnings measures are likely to be related, they potentially capture different effects.

We are interested in both accounting for skill differences across workers as well as the resources available to households and in combination these variables serve as proxies for these

\footnotetext{
${ }^{20}$ This is the same definition of a separation used in the Quarterly Workforce Indicators, and is meant to avoid counting seasonal workers as separators. By using this definition, we also avoid including workers recalled to their former employer, who may not have engaged in a job search.

${ }^{21}$ Our estimation results are qualitatively unchanged if we instead impose an 8-quarter tenure restriction. However, the more stringent tenure restriction reduces our sample size by about 40 percent (see Table 2 ). 
different effects. We also include additional measures of the prior job history of the separator. For the 2 years prior to separation, we count the quarters in which the workers earned wages from their former employer, indicating their tenure at that employer. We also count the number of jobs held by a worker in the last 2 years, an indication of job stability and experience with search. Lastly, we include a measure of the earnings in the quarter of separation as a control for when in the quarter the worker separated.

As a sample restriction, we require that the displaced worker had total earnings of at least $\$ 15,000$ in the previous year and that they lost at least half of their total annual earnings due to the separation. To focus on lower-earning workers, for which the spatial mismatch hypothesis has been emphasized, we also exclude those with total earnings of greater than $\$ 40,000$ per year. $^{22}$

Also crucial to our assumptions of the effect of job accessibility on search outcomes is defining where a worker lives at the time of their separation. Naturally, we must be able to establish that a worker lives in one of the metropolitan areas of this study, and we must be able to identify a neighborhood, or census tract, in which they reside. We make use of administrative data links carried out at the Census Bureau to match wage records, by Protected Identification Key (PIK), to federal administrative records on place of residence, known as the Composite Person Record (CPR). ${ }^{23}$ (A PIK is used in place of a Social Security Number for administrative matching purposes.) The available addresses for each individual in a year are de-duplicated and a

\footnotetext{
${ }^{22}$ According to the Current Population Survey Annual Social and Economic Supplement estimates for 2000 to 2005, median earnings for full-time, year-round workers ranged from $\$ 25,278$ to $\$ 28,567$ (around $\$ 32,000$ in 2010 dollars).

${ }^{23}$ The LEHD program uses residence locations as an input to an imputation process for matching establishments to workers, when that link cannot be determined from wage records. OTM data also makes use of CPR residence data to present jobs data by home location and commuting flows. Most place of residence records are received from the Internal Revenue Service. 
single address, denoted by a Housing Unit ID, is geocoded to a county, census tract, or census block. For this study, we use the worker's place of residence in the calendar year prior to the separation. $^{24}$

In order to characterize the demographics of job searchers, we match workers to responses in the 2000 Decennial Census short form. Like the match to the CPR, wage records can be matched to Census responses by way of a PIK..$^{25}$ For control variables and sub-sample analyses, we use a worker's sex, race, ethnicity, age, and marital status. We construct a marital status variable by using the response indicating a person's relationship to head of household in 2000. For a separated worker's year 2000 household, we identify whether the worker is reported to be the spouse (husband/wife) or unmarried partner of the head of a household or, in a case where the worker is the head of household, whether another household member is reported to have such a relationship to the worker. We then refer to the Housing Unit ID matched to the separated worker in the CPR, and observe whether their spouse or partner from 2000 has been matched to the same unit (by way of a PIK). Henceforth, we refer to all job separators linked by housing unit to a spouse or partner from 2000 as "married," even though we cannot verify their domestic status in the year of separation. We also create an additional control variable for annual household earnings by matching a job separator's spouse to the EHF and calculating earnings from all jobs in the year prior to separation.

\footnotetext{
${ }^{24}$ Because the CPR is annual, it is not possible to know if the reported residence in the year of the worker's separation specifies a residence prior or subsequent to the separation. Therefore, using place of residence in the same year as the separation occurred might define job accessibility based on a location where the worker moved after the separation, possibly after finding a new job. To avoid this, we use the worker's place of residence in the calendar year prior to the year in which the separation occurred. Because of the 1 year tenure requirement we impose, this address is likely to have been current for the separated job for most workers.

${ }^{25}$ The Census Bureau uses a probabilistic matching process to assign a PIK to survey responses. Over 90 percent of responses can be matched to a PIK using personally identifying information.
} 
Table 1 provides a summary of the sample restrictions imposed and the resulting sample sizes (rounded to the nearest 1,000 ). By requiring that job separators satisfy tenure and earnings restrictions, that they can be matched to a residence in a study area and to the 2000 Census, and that they are aged 20 to 64 at the time of separation, we arrive at a sample size of $1,837,000$ (with the possibility that a worker could appear multiple times).

As a next, crucial step for our identification strategy, we select displaced workers who have separated from an employer due to a mass layoff. Within the LEHD data infrastructure, we make use of the Employer Characteristics File (ECF), which, for all employers in a state, tracks the number of workers receiving earnings in each quarter, as well as the an employer's ownership type and industry. Each employer operation in a state has a State Employer Identification Number (SEIN) used to track its data longitudinally and to match in workers from the EHF earning wages at that employer. We use the SEIN as the definition of an employer in this analysis, whether they are a single-unit or multi-establishment employer. ${ }^{26}$

We use three criteria to identify mass displacement events. First, the employer should have at least 25 employees at the start of the quarter when the layoffs begin. ${ }^{27}$ The main purpose of avoiding especially small employers is that for very small employers the attrition of a small number of workers can yield a large percentage change in employment. ${ }^{28}$ This size restriction

\footnotetext{
${ }^{26}$ The ES-202/QCEW data also has information at the establishment-level for multi-unit firms with multiple locations in the same state. This is known as information at the SEINUNIT level. The Unemployment Insurance wage record data is only linked to the SEIN-level data. The LEHD program has developed an imputation procedure for allocating workers at the SEIN level to the SEINUNIT level. We will explore the sensitivity of our results to using the establishment-level data as the definition of an employer using this imputed allocation in future versions. ${ }^{27}$ Beginning-of-quarter employment counts only the wage records of workers employed in both the previous and current quarter. A worker employed in both quarters is assumed to be working at that employer on the first day of the current quarter. Thus, beginning-of-quarter employment is a good way to measure the total number of positions existing at an employer at a point in time.

${ }^{28}$ Some other studies of mass displacement use a threshold of 50 employees. In the future, we intend to repeat our analysis with higher cutoffs of firm size. 
reduces the separator sample size by about 20 percent. Second, the employer should lose at least 30 percent of its workers over a 4-quarter period, which reduces the sample by another 70 percent. We allow displacements to occur over multiple quarters to include workers leaving in anticipation or prior to a particular mass layoff quarter, as well as those leaving shortly afterwards. Third, we exclude all displacement events that appear to be the result of changed ownership or structure, rather than a contraction of positions. LEHD has created a SuccessorPredecessor File (SPF) that identifies cases where an SEIN dies or contracts and either 80 percent of its workers begin earning wages from to another employer, or where 80 percent of another employer's workers come from the contracted employer. Such cases of restructuring are not indicative of a mass layoff, and thus we exclude them. This exclusion removes another 60 percent of separators. The resulting sample is a set of approximately 200,000 displaced workers.

We present summary statistics of our sample in Table 2 . Our sample is fairly representative of the metropolitan areas in our study in terms of demographic characteristics, with approximately 59 percent of searchers being non-Hispanic Whites, 25 percent non-Hispanic Blacks, and 12 percent Hispanic. Workers younger than 35 years and older than 55 years account for 14 and 11 percent of the sample, respectively. We classify 28 percent of the sample as married, though this is likely an underestimate due to inaccuracies in the administrative data matching techniques used. Total earnings are widely distributed across earnings categories. The vast majority of displaced workers had only derived income from one job in the previous year, and thus lost 100 percent of their pre-displacement earnings. The continuous variables show the relative size earnings from the household, all jobs, the lost job, and the last quarter of the lost job. On top of the minimum 1-year tenure requirement, 60 percent of workers had 2 or more years of tenure at their employer. We also constructed a variable estimating whether the worker 
commuted less than 20 minutes, or more than 40 minutes to their previous job. These commute duration indicators control for a job searcher's willingness to undertake long commutes. ${ }^{29} \mathrm{We}$ aggregated industries into a set of five groups based on broad similarities in workforce specialization and hiring methods. ${ }^{30}$ Displacements occurred across a wide range of industries with manufacturing and construction accounting for the largest share. Displacements were fairly evenly spread across years, and quarters within those years, with 2001 and 2002 having the most.

Table 3 presents a summary of the spatial mismatch (job accessibility and competing searchers) variables for the sample of displaced workers. The logged versions are the variables used in the ordered logistic regressions. Note that while average job accessibility and competing searchers are of similar quantities, job accessibility has a much higher standard deviation. If job and residence density were completely flat, with all locations having equal quantities, the measures would be exactly equal. Thus, the higher variance of jobs is indicative of the lumpiness of employment centers in cities. The pooled sample is categorized into subsamples of interest based on the demographic variables listed in Table 2. Note that these summaries do not control

\footnotetext{
${ }^{29}$ Travel time to displaced job is calculated by matching MPO-estimated travel times to LEHD job location and residence location data. Employer locations are listed in the ECF, but for some workers it is not possible to precisely locate their place of work. First, workers at multi-unit employers may not have a reported place of work in the stateprovided administrative data. LEHD imputes these workers to a workplace of the employer based on where the worker lives and the period of their employment. In these cases, we use the first implicate of this imputation as their place of work. Second, the geographic location of workplaces may be imprecise in a low share of cases, or the location may be outside of our MPO study areas. In either case we would not be able to match a travel time to a workplace destination. For this small share of workers missing previous job travel times (about 9 percent), we substitute the mean previous job travel time of workers in the same county of residence with the same sex and race group (either non-Hispanic White or not of that category for this purpose).

${ }^{30}$ We define the five industry groups from NAICS industry sectors as follows. The "Manufacturing" sector also includes all goods-producing sectors, including Construction, Agriculture, and Mining. "Distribution" includes Transportation and Warehousing, Wholesale, Retail, and Utilities. The "Professional services" sector includes Information, Finance and Insurance, Real Estate and Rental and Leasing, Professional, Scientific, and Technical Services, and Management of Companies and Enterprises. "Institutional services" include Educational Services, Health Care and Social Assistance, Public Administration. "Other services" includes Administrative and Support and Waste Management and Remediation Services, Arts, Entertainment, and Recreation, Accommodation and Food Services, and Other Services.

28
} 
for metropolitan area fixed effects. The sub-sampling with the greatest differentials is race/ethnicity, where non-Hispanic Blacks live in tracts with the greatest accessibility to jobs. However, non-Hispanic Blacks also have the greatest number of competing searchers that can reach those same jobs. We find that job accessibility and an abundance of competing searchers are somewhat intertwined, with a partial correlation of 0.684 within the 0 to 20 minute range (this correlation controls for the effects of metropolitan areas). Nevertheless, there is still substantial pair-wise variation between these measures.

Having discussed the sample selection and control variables, we now discuss our measure of job search outcomes. Once again, we use wage records from the EHF to identify any new streams of earnings, from a different employer, during the quarter of their separation or in the subsequent year. At this point, we only check for new jobs within the same state, so we do not account for hiring of workers into jobs in other states (or for those entering self-employment or federal employment). We define an accession, or a new job, as beginning in the first quarter in which the worker earns wages from a new employer. We require that the worker has not earned wages from that employer for 2 years prior to the separation. In the future, we will investigate whether this restriction is excessive, and whether previous jobs are an important source of replacement income following a separation.

From this new hire variable, we construct a measure of joblessness duration, our main dependent variables for our empirical specifications. Our duration measure indicates whether a job was obtained in the quarter of separation, in the 4 following quarters, or not at all within that period. Because the literature on job displacement has found that it can take several quarters before displaced workers are able to replace the earnings lost in their previous job, the first job a displaced worker obtains may not have earnings commensurate to the lost job. As an alternate 29 
job search measure that also gives some indication of the quality of a job, we construct a second variable to measure earnings replacement. We identify the first quarter in which a separated worker has positive earnings at a job that, in either that quarter or the next, pays at least 75 percent of the quarterly wage that the individual earned prior to displacement. As an illustration of this distinction, we may identify a worker as obtaining a low wage new job in the quarter displacement, but not obtaining a job that replaces the earnings from the lost job (at 75 percent) until several quarters later. In the future, we will also examine other thresholds of earnings replacement and attachment to new jobs. For example, we might only consider new jobs that last at least 1 full quarter. ${ }^{31}$

Table 4 summarizes the re-employment of the displaced workers in our sample, with the hiring result in each quarter representing an outcome category in our ordered logistic regression. In Panel A of Table 4, it can be seen that nearly one-third (32 percent) of displaced workers obtain some new job within the same quarter, and over one-half (51 percent) within one quarter after displacement. Obtaining any new job slows down after that with about 28 percent still jobless after 4 quarters. In contrast, Panel B shows that workers are less likely to find jobs that earn at least 75 percent of their previous earnings. By the end of 1 quarter after displacement, only one-third ( 33 percent) have such a job. After 4 quarters, 45 percent of workers have still not obtained a new job with earnings comparable to their previous job.

\footnotetext{
${ }^{31}$ The Quarterly Workforce Indicators (QWI) that are a key public use product from the LEHD data infrastructure show very high rates of worker turnover for workers with short (less than 1 quarter) attachments relative to those who have at least 1 quarter of attachment to firms. 


\section{Estimation Results}

The empirical results of estimating the effects of job accessibility and other key variables using the specification described in section 3 on the duration of joblessness for displaced lowerincome workers finding any job using an ordered logit model are presented in Table 5. Results for finding any job and for finding a comparable job (that is, one earning at least 75 percent of the lost job's earnings) are presented side by side. Predicted effects for changes in the spatial mismatch variables are presented in Table 6. Estimation results for sub-populations and industryspecific results are presented in Table 7. A positive coefficient estimate is interpretable as indicating that an increase in the variable leads to longer search durations, while a negative coefficient estimate indicates that an increase in the variable leads to shorter search durations. ${ }^{32}$

In our primary specification reported in Table 5, including the full sample of displaced workers, we find that signs of the spatial mismatch variables follow intuition, with more job opportunities in the 0 to 20 minute travel time range being associated with reduced job search duration, and with more competing searchers being associated with increased job search duration. For almost all spatial mismatch variables and control variables the effects are statistically significant at a p-value of below the 0.01 level. We find that the competing searcher effects are larger in magnitude than the job accessibility effects. As is noted earlier, we

\footnotetext{
${ }^{32}$ The ordered logistic specification assumes that the odds ratios associated with outcome category combinations do not vary with respect to covariates. As a result, coefficients (except for the outcome-specific intercepts) also do not vary across outcome categories. Similar to a logistic regression with a dichotomous dependent variable, a positive coefficient implies an increased likelihood of a higher outcome category. The size of predicted impacts depend on values of other variables. To get a better sense of the quantitative importance of effects, we report predicted transition rates to employment in Table 6, where all other variables are held at their pooled means (including binary variables). 
performed robustness checks on the range of the spatial mismatch variables, testing ranges of 0 to 30 minutes and 0 to 40 minutes, which had qualitatively similar results. ${ }^{33}$

We note that in all of the specifications considered, almost all of the control variables are statistically significant at high levels of confidence, and have effects in the predicted directions. The Pseudo R-squared is 0.0326 , suggesting that there is still a substantial amount of unexplained heterogeneity. Women have longer job searches than men, and Non-Hispanic Blacks, Hispanics, and those non-Hispanics of Other races all have longer job searches than Non-Hispanic Whites, the excluded group. Search duration monotonically and substantially increases with age. The finding of age effects is consistent with the well-known finding in the labor literature that older workers have lower incidence of unemployment but longer durations as well as lower propensity for geographic mobility. Married searchers tend to find a new job more rapidly.

Holding total household earnings and earnings from all jobs constant, higher earnings from the displaced job yields lower durations. This finding is consistent with the findings in the literature that higher skilled workers have lower durations. ${ }^{34}$ But interestingly, holding earnings from the displaced job constant, higher household earnings and higher earnings from all jobs tend to have longer duration searches. These latter patterns are consistent with the hypothesis that alternate sources of income support allow a displaced worker to be less aggressive in their

\footnotetext{
${ }^{33}$ For finding any job, with the 30 minute range, job accessibility has a coefficient of -0.016 (std. err. of 0.008 ) and competing searchers a coefficient of 0.090 (std. err. of 0.016 ). Using the 40 minute range, job accessibility has a coefficient of -0.023 (std. err. of 0.009) and competing searchers a coefficient of 0.183 (std. err. of 0.030 ).

${ }^{34}$ For the literature on unemployment duration by age and education and other factors, see, e.g., Darby et al. 1985 and Abraham and Shimer 2001. Note that this finding is also consistent with the notion of positive selection between productive traits and location decision of workers in combination with persistence in job accessibility from time of the initial location decision to the time of displacement.

32
} 
search, or possibly to hold out for a higher quality job. Consistent with this hypothesis, the duration effects are substantially lower for obtaining a comparable earning job. ${ }^{35}$

Recall that we are restricting attention to workers earning between $\$ 15,000$ and $\$ 40,000$ annually in the prior job, but even within this range prior earnings has a large and important effect. This is not surprising since, as we have discussed, prior earnings should capture a wide range of sources of worker heterogeneity.

Turning to other variables describing the lost job, searchers with longer travel times to their lost jobs find new jobs sooner, possibly indicating an increased ability or willingness to commute long distances, resulting in a greater set of potential job matches. Displaced workers with longer tenure at their former employer are slower to find new jobs while those with more jobs in the last 2 years find a new job sooner (though the effect is not statistically significant). These estimates are consistent with long tenure workers not separating on a voluntary basis and perhaps, not being prepared for a job search. Relative to being displaced from a manufacturing job, all displacements resulted in shorter job searches except for those displaced from positions in more institutionalized industries, including healthcare, education, and public administration, perhaps because these industries have more complex hiring processes.

The specifications in Table 5 all include year, season, and metropolitan area fixed effects which we do not report for ease of exposition. Briefly summarizing, we find that displacements in 2000, before the recession, result in shorter periods of joblessness than displacements in later years. Displacements in quarters 2 and 4, from April through June and October through

\footnotetext{
${ }^{35}$ As reported, higher earnings in the quarter of separation also result in a longer search, possibly because a worker may have continued to hold the job until late in the quarter, or because a severance payment cushioned the transition into job search. We regard the inclusion of the earnings in the quarter of separation as primarily a way to address these measurement concerns and not of particular economic interest. 33
} 
December, result in the longest job searches. Although this result is somewhat surprising given the increase in employment over summer months, it may be that displaced workers are looking for more permanent jobs than are typical posted vacancies at that time, or that summer vacancies have already been filled by the time they begin searching. Metropolitan area fixed effects are also significant and important, but cannot be reported due to agreements with state partners. The estimates of control variable coefficients are fairly consistent across specifications and subsamples, but will not be reported from here on.

The upper panel of Table 6 presents predicted effects on the transition rate to employment evaluated at the means of the other variables, showing the effect of increasing each spatial mismatch variable from its value at the $10^{\text {th }}$ to $90^{\text {th }}$ percentile on the probability of obtaining employment in each search quarter. In Table $6,10^{\text {th }}$ and $90^{\text {th }}$ percentile probabilities are under the columns "low" and "high" respectively, with the difference given in the "effect" column. The predicted effect of having a half higher as compared to lower accessibility to jobs is shown to be associated with a 1.0 percentage point increase in the probability of obtaining employment within the same quarter. The cumulative predicted effect for having high as opposed to low job accessibility for obtaining a job by 1 quarter is about 1.2 percentage points; thus job accessibility has most of its effect immediately. This immediate effect should be viewed in the context of the mean probability of workers finding a job, which is about 30.6 percent in the same quarter, and a cumulative 51.4 percent by quarter 1 . It is important to remember that these predicted effects are calculated at the total sample means; if a subsample of interest has different means of say, earnings, then the calculation will differ.

Compared to job accessibility, having more competing searchers has a larger magnitude increase on job search duration (even though the standard deviation of competing searchers is 34 
less than that of job accessibility). Having more competing searchers near the jobs one is seeking reduces the probability of getting a job by -2.4 percent in the quarter of separation, and the cumulative effect after one quarter is -2.8 percent. This result shows that it does not just matter where a worker lives in relation to jobs, but also where they live in relation to other potential job seekers. These results suggest that competing searchers are more important than job accessibility, though the two measures are somewhat related.

Regarding the effect of spatial mismatch measures for obtaining a comparable job to the one lost, the results are broadly similar to those for any job. The magnitude of the competing searcher effect is relatively smaller, which could indicate that other factors, such as job match quality, play an important role in the search for a comparable job. The control variables have similar effects as in the previous specification, with a couple of notable exceptions as noted earlier in the earnings discussion. Non-Hispanic Blacks and Hispanic workers were even less likely to find a comparable job compared to Non-Hispanic Whites. While being displaced from a job in institutional industries increased the time to find any job relative to the manufacturing industry, it had no significant effect on the time to find a comparable job. The predicted effects of finding a comparable job reflect this smaller magnitude, with greater job accessibility increasing the probability of finding a job within 1 quarter by 1.1 percentage points, and with more competing searchers resulting in a -1.8 percentage point change in the probability of finding a job within 1 quarter.

We now examine whether specific populations of displaced workers are especially sensitive to spatial mismatch by repeating the previous specifications on subsamples by sex, race/ethnicity, age, and industry. These results for finding any job and a comparable job are presented in Table 7. We only list the estimates of the spatial mismatch parameters. Sample sizes 35 
correspond to the sample shares listed in Table 2. The same set of control variables is used for each sample (with the exception of the particular control variable that defines the sub-population sample), and most of the associated parameters have similar estimates for each subsample.

In these subsamples, we typically find that at least one of the spatial mismatch variables has a significant effect in the expected direction, and only occasionally does one have an unexpected sign. We also find interesting differences in the quantitative impact of the accessibility and competing searchers measures across the subsamples. Based upon point estimates, job accessibility has a larger effect on men relative to women, on Hispanics relative to other ethnic groups, and on older workers relative to younger workers. For competing searchers, the point estimates yield larger effects for men relative to women, Hispanics relative to other ethnic groups, and older workers compared to younger workers. In all of the cases that we have noted with the largest magnitude of point estimates, the estimated impact is statistically different from zero at least the 0.05 level.

We have also examined subpopulations of job searchers defined by the industry which they were separated from, and with job accessibility and competing searcher measures specific to jobs in that industry. These results indicate that industry-specific job accessibility may have an even greater magnitude effect on the duration of joblessness than overall job accessibility does, at least for some sectors. The effects all have the expected sign, and for the manufacturing sector, the effects have an especially large magnitude. For displaced manufacturing workers, the effect of an increase from the $10^{\text {th }}$ to $90^{\text {th }}$ percentile in manufacturing job accessibility is to increase the probability of obtaining a new job (of any industry) within 1 quarter by over 3.1 percentage points, compared to an average probability of about 25 percent. The effect of having more 
competing searchers for manufacturing jobs lowers the probability obtaining any job by over 4.7 percentage points.

In sum, we have attempted to model the effects of relevant factors, including spatial mismatch variables, on job search outcomes. Based on the intuitive and strong results of the numerous control variables we have included for demographic, household, and earnings history variables, as well as year, season, and metropolitan area fixed effects, we believe that we are appropriately modeling job search outcomes. We find that greater job accessibility reduces search duration and that more competing searchers lengthen search duration. Nevertheless, in light of the numerous factors influencing job search, we show that the effect of spatial mismatch is not trivial, but also is not a dominant effect. Some of the stronger results are for industryspecific measures of job accessibility, where the link between search frictions and search outcomes may be especially strong because of industry specific skills. In future work, we plan to develop spatial mismatch measures that are even more specific to particular classes of job searchers.

\section{Conclusions and Next Steps}

This paper summarizes early findings from a project aimed at better understanding the role of spatial mismatch in the matching of heterogeneous lower-income workers with heterogeneous employers. We can contribute to the previous literature in that our data infrastructure permits the analysis of how geographically granular, individual-specific, and vacancy-based job accessibility measures impact a variety of job-search related outcomes, using identification strategies that address the fact that workers are not randomly distributed across space. Our initial results suggest that both aspects of spatial mismatch - accessibility to jobs and competition from other 37 
searchers - have a significant but modest impact on the duration of joblessness for displaced lower-income workers. We intend to enhance the analysis along four primary dimensions to reflect the promise of our data and our approach.

First, we will continue to expand the number of metropolitan areas in our analysis. Initially, we will increase our sample of Midwestern areas; this will increase our sample sizes and allow us to present more disaggregated results. Beyond that, we will add further areas to make our results more nationally representative and to allow for more control variables (including metropolitan area characteristics). We will also expand the analysis longitudinally to include 2006 to 2009 data, and new years as they become available.

Because the use of travel time, rather than distance, is essential to our measure of urban accessibility, we will need to either obtain more MPO travel time data from new areas, or develop measures of travel time from alternative sources. The Census 2000 journey-to-work data contains only reported travel time along routes that were actually traveled, but we need a full matrix of tract-to-tract travel times for each area. We are considering methodologies for developing an imputed travel time for unobserved tract-to-tract journeys based on the observed travel times. We are also in the process of obtaining transit-based travel time measures and considering options of developing our own transit-based measure. For lower-income individuals (and for individuals working in densely populated urban areas) the exclusion of transit-based job accessibility measures may be problematic since these workers are more likely to use public transportation (a substantial number of workers in our cities use public transit). Because public transportation travel times are generally greater than automobile travel times for the same trips, workers reliant on public transportation may have curtailed job accessibility. 
Second, we will refine our measure of job accessibility. Currently, by arbitrarily defining an auto commute time range of 20 minutes, within which all jobs are considered to be equally nearby, we are only using a small portion of the observed variation. We are currently experimenting with an adaptive index based measure. This measure would differ from the typical "gravity index" approach, where job accessibility is the sum of jobs in all zones divided by the travel time to each zone raised to some exponent. Rather, we would use the observed commuting patterns in LEHD data of groups of workers within cities to construct customized measures. For our measure of job accessibility, we will begin to use LEHD infrastructure data (rather than publicly available OTM data) to construct access measures based on where new hires occur or where new employers are locating. We will also be able to use demographic variables matched to LEHD employment data to measure access to workers or new hires in the same race, ethnicity, sex, or education level as the job seeker. Ultimately, we may produce a separate analysis for the purpose of exploring variation in spatial mismatch measures by population subsamples and across areas.

Third, we will take more steps to ensure that the estimated effect of job accessibility is not biased due to unobserved factors affecting residential location choices. We will add a longitudinal difference to our measure of job accessibility to reflect how job accessibility differs at the time of a job search from what the displaced worker might have reasonably expected for that location. For example, contemporaneous job accessibility could be measured as the difference in job accessibility from a 5-year average for that location. Use of this measure would also require the inclusion of area-year fixed effects to soak up regional trends. In addition, we will introduce control variables reflecting a job searcher's ties to a residential location, including duration of residence in the current location, and household ties. We are also considering 39 
whether to add neighborhood-based variables, in addition to the spatial mismatch variables, that may be important for job search outcomes. However, because neighborhood-level variables, such as home ownership rates, the age of the housing stock, and population density, vary at the same level as spatial mismatch measures, we will have to examine whether there is still sufficient independent variation to identify the results.

Finally, we will further utilize the LEHD infrastructure data to develop additional outcome variables (beyond the vacancy-based job accessibility measure mentioned above). In addition to measuring whether a worker obtains a job and how the earnings compare to the displaced job, we will measure whether the new job lasts at least 1 quarter to gauge long-term attachment to that job. We will also evaluate earnings replacement following a separation and explore transitions into new industries and locations. 
Figure 1. Illustrative Job Accessibility Measures

A. Monocentric City

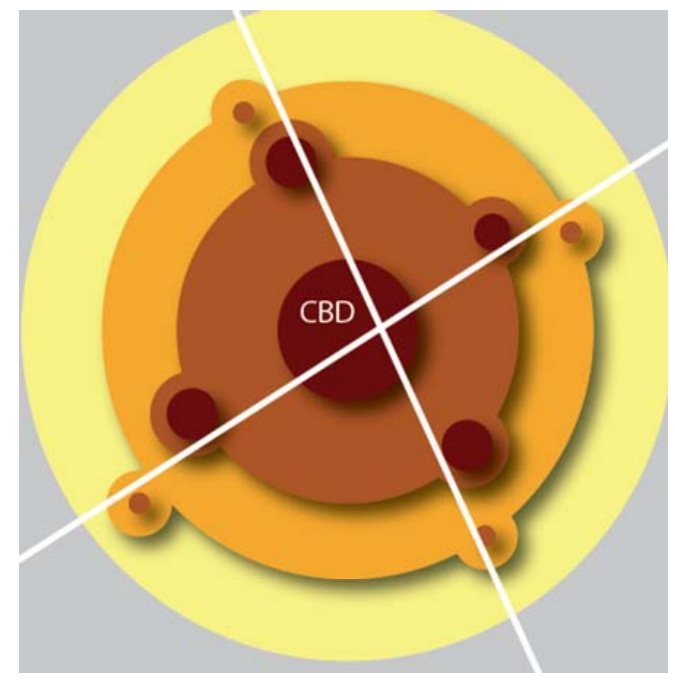

B. Polycentric City

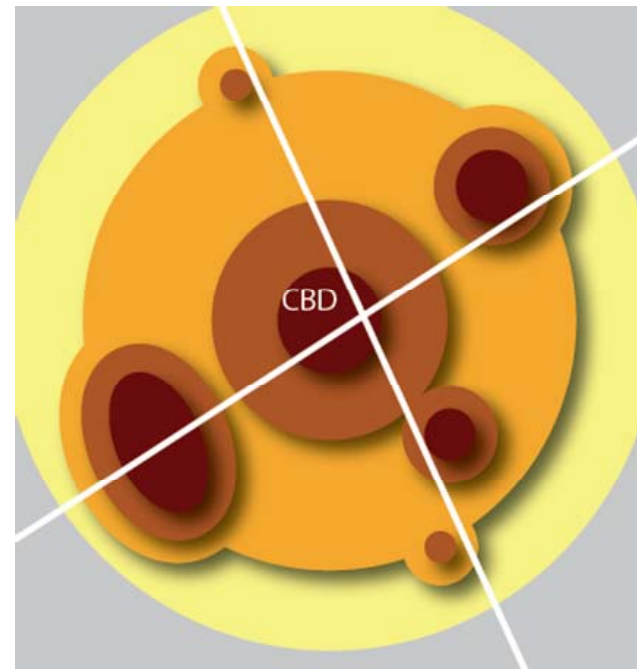

These illustrations represent the variation in job accessibility across city types. Darker shading indicates areas with higher job accessibility, lines indicate transportation links. This figure does not contain actual data. 
Table 1. Sample construction

\begin{tabular}{lr}
\hline Sample restriction & Sample size \\
\hline Restricted sample of separators with $\geq 1$ year tenure & $1,837,000$ \\
Employer had $>25$ employees before separation & $1,509,000$ \\
Employer lost $>30$ percent of workers over year & 480,000 \\
Employer did not transition to successor & 200,000 \\
\hline
\end{tabular}

Notes: The sample is constructed from LEHD infrastructure files from 1998 to 2006. Restrictions include that worker separated from a job between 2000 and 2005 and was not recalled, the separator's residence can be geocoded to a census tract in a study area, that the worker can be matched to the 2000 Census with an age between 20 and 64 at the time of the separation, that their total earnings were between $\$ 15,000$ and $\$ 40,000$ in the year before separation - and that the lost job accounted for at least half of those earnings. Sample sizes are rounded to the nearest 1,000. Restrictions on employer size, contraction, and transitions define a sample of job separators that were subject to mass displacement events.

Source: Authors' tabulations of Longitudinal Employer-Household Dynamics data matched to Census 2000. 
2. Summary statistics

\begin{tabular}{|c|c|c|}
\hline Variable & Category & Mean \\
\hline \multirow[t]{2}{*}{ Sex } & Male & $48.2 \%$ \\
\hline & Female & $51.8 \%$ \\
\hline \multirow[t]{4}{*}{ Race/Ethnicity } & White not-Hispanic & $59.1 \%$ \\
\hline & Black not-Hispanic & $25.3 \%$ \\
\hline & Hispanic & $11.9 \%$ \\
\hline & Other race, not-Hispanic & $3.8 \%$ \\
\hline \multirow[t]{5}{*}{ Age at time of separation } & 20 to 24 & $13.8 \%$ \\
\hline & 25 to 34 & $32.5 \%$ \\
\hline & 35 to 44 & $24.6 \%$ \\
\hline & 45 to 54 & $18.0 \%$ \\
\hline & 55 to 64 & $11.0 \%$ \\
\hline \multirow[t]{2}{*}{ Marital or partner status } & Not married & $72.0 \%$ \\
\hline & Married & $28.0 \%$ \\
\hline \multirow{5}{*}{$\begin{array}{l}\text { Total pre-separation } \\
\text { earnings from all jobs } \\
\text { (annual) }\end{array}$} & $\$ 15,000$ to $\$ 19,999$ & $19.2 \%$ \\
\hline & $\$ 20,000$ to $\$ 24,999$ & $21.8 \%$ \\
\hline & $\$ 25,000$ to $\$ 29,999$ & $21.7 \%$ \\
\hline & $\$ 30,000$ to $\$ 34,999$ & $20.1 \%$ \\
\hline & $\$ 35,000$ to $\$ 40,000$ & $17.2 \%$ \\
\hline \multirow{2}{*}{$\begin{array}{l}\text { Share of total pre-separation } \\
\text { earnings lost }\end{array}$} & $>50 \%$ and $<100 \%$ & $23.4 \%$ \\
\hline & $100 \%$ & $76.6 \%$ \\
\hline \multirow[t]{5}{*}{ Tenure of separated job } & 4 quarters & $11.8 \%$ \\
\hline & 5 quarters & $10.6 \%$ \\
\hline & 6 quarters & $8.9 \%$ \\
\hline & 7 quarters & $9.8 \%$ \\
\hline & 8 or more quarters & $58.9 \%$ \\
\hline \multirow{3}{*}{$\begin{array}{l}\text { Travel time to separated job } \\
\text { (estimated auto commute) }\end{array}$} & $\leq 20$ minutes & $34.5 \%$ \\
\hline & 20 to 40 minutes & $37.4 \%$ \\
\hline & $>40$ minutes & $28.1 \%$ \\
\hline \multirow{5}{*}{$\begin{array}{l}\text { Industry grouping of job } \\
\text { separated from }\end{array}$} & Manufacturing & $26.6 \%$ \\
\hline & Distribution & $19.0 \%$ \\
\hline & Professional & $17.6 \%$ \\
\hline & Institutional & $15.8 \%$ \\
\hline & Other services & $21.0 \%$ \\
\hline
\end{tabular}

Notes: Dollar amounts not adjusted for changes in price index. Those listed as White not Hispanic, Black not-Hispanic, and other race not-Hispanic each refer to a race alone category, and are hereafter referred to as White, Black and Other race.

Source: Authors' tabulations of Longitudinal Employer-Household Dynamics data matched to Census 2000. 
2. Summary statistics (continued)

\begin{tabular}{|c|c|c|c|}
\hline Variable & Category & Mean & Std. Dev. \\
\hline \multirow[t]{10}{*}{ Earnings history variables } & Household earnings & $\$ 36,007$ & $\$ 24,879$ \\
\hline & Total earnings & $\$ 27,199$ & $\$ 6,937$ \\
\hline & Earnings from lost job & $\$ 26,441$ & $\$ 7,133$ \\
\hline & Earnings in qtr. of sep. & $\$ 4,634$ & $\$ 5,941$ \\
\hline & Log Household earnings & 10.36 & 0.47 \\
\hline & Log Total earnings & 10.18 & 0.27 \\
\hline & Log Earnings from lost job & 10.14 & 0.29 \\
\hline & Log Earnings in qtr. of sep. & 8.00 & 1.15 \\
\hline & Job tenure at separated job & 6.93 & 1.47 \\
\hline & Count of jobs in last 2 years & 1.90 & 1.26 \\
\hline \multirow[t]{6}{*}{ Year separated from job } & 2000 & $15.2 \%$ & \\
\hline & 2001 & $19.3 \%$ & \\
\hline & 2002 & $21.5 \%$ & \\
\hline & 2003 & $15.0 \%$ & \\
\hline & 2004 & $16.5 \%$ & \\
\hline & 2005 & $12.6 \%$ & \\
\hline \multirow[t]{4}{*}{ Quarter separated from job } & 1 & $23.5 \%$ & \\
\hline & 2 & $25.9 \%$ & \\
\hline & 3 & $24.6 \%$ & \\
\hline & 4 & $26.0 \%$ & \\
\hline
\end{tabular}


Table 3. Spatial mismatch variables

\begin{tabular}{llrr}
\hline Sample & Measure & Mean & Std. Dev. \\
\hline All displaced workers Job accessibility: 0-20 minutes & 109,042 & 89,038 \\
& Competing searchers: 0-20 minutes & 110,144 & 64,896 \\
& Log job accessibility & 11.21 & 1.01 \\
& Log competing searchers & 11.42 & 0.67 \\
\hline Male & Log job accessibility & 11.17 & 1.03 \\
& Log competing searchers & 11.40 & 0.67 \\
\hline Female & Log job accessibility & 11.24 & 0.99 \\
& Log competing searchers & 11.43 & 0.67 \\
\hline White & Log job accessibility & 11.15 & 1.02 \\
& Log competing searchers & 11.33 & 0.74 \\
\hline Black & Log job accessibility & 11.51 & 0.89 \\
& Log competing searchers & 11.68 & 0.52 \\
\hline Hispanic & Log job accessibility & 10.83 & 1.06 \\
& Log competing searchers & 11.32 & 0.47 \\
\hline Age 20 to 34 & Log job accessibility & 11.20 & 1.00 \\
& Log competing searchers & 11.41 & 0.67 \\
\hline Age 35 to 54 & Log job accessibility & 11.23 & 1.01 \\
& Log competing searchers & 11.44 & 0.67 \\
\hline Age 55 to 64 & Log job accessibility & 11.16 & 1.01 \\
& Log competing searchers & 11.39 & 0.67 \\
\hline Manufacturing & Log industry sector job accessibility & 8.99 & 1.08 \\
& Log industry sec. competing searchers & 9.21 & 0.72 \\
\hline Distribution & Log industry sector job accessibility & 9.85 & 0.97 \\
& Log industry sec. competing searchers & 10.01 & 0.62 \\
\hline Professional & Log industry sector job accessibility & 9.21 & 1.17 \\
& Log industry sec. competing searchers & 9.56 & 0.69 \\
\hline Institutional & Log industry sector job accessibility & 9.57 & 1.07 \\
& Log industry sec. competing searchers & 9.75 & 0.71 \\
\hline Other services & Log industry sector job accessibility & 9.96 & 1.03 \\
& Log industry sec. competing searchers & 10.21 & 0.66 \\
\hline & & &
\end{tabular}

Notes: Job accessibility measures the total number of jobs located within a travel time range of 0 to 20 minutes of a displaced worker's home location. Competing searchers measures the average number of employed workers that can reach those jobs within less than 20 minutes from their home locations. See formulas in text.

Source: Authors' tabulations using publicly available OnTheMap employment totals and MPO travel data for LEHD sample of job separators. 
Table 4. Transitions to employment following a separation

A. Hired to any job

\begin{tabular}{lrr}
\hline Quarter hired & Percent of separators & Cumulative \\
\hline Same quarter as separation & $32.0 \%$ & $32.0 \%$ \\
1 quarter after & $19.5 \%$ & $51.4 \%$ \\
2 quarters after & $10.5 \%$ & $61.9 \%$ \\
3 quarters after & $6.3 \%$ & $68.3 \%$ \\
4 quarters after & $4.2 \%$ & $72.4 \%$ \\
Not hired within 4 quarters & $27.6 \%$ & $100.0 \%$ \\
\hline Total & $100.0 \%$ & \\
\hline
\end{tabular}

B. Hired to a job earning at least 75 percent of lost job's earnings

\begin{tabular}{lrr}
\hline Quarter hired & Percent of separators & Cumulative \\
\hline Same quarter as separation & $8.3 \%$ & $8.3 \%$ \\
1 quarter after & $25.0 \%$ & $33.4 \%$ \\
2 quarters after & $10.2 \%$ & $43.6 \%$ \\
3 quarters after & $6.6 \%$ & $50.1 \%$ \\
4 quarters after & $4.9 \%$ & $55.0 \%$ \\
Not hired within 4 quarters & $45.0 \%$ & $100.0 \%$ \\
\hline Total & $100.0 \%$ & \\
\hline
\end{tabular}

Notes: The first quarter in which a job seeker earns wages from a new job is the quarter of hiring. The workers cannot have earned wages from that employer in the previous two years. For panel $\mathrm{B}$, the new job must earn $75 \%$ of the quarterly earnings of the job held before the separation. Transitions used as outcome variable in ordered logistic regressions.

Source: Authors' tabulations of Longitudinal Employer-Household Dynamics data matched to Census 2000. 
Table 5. Ordered logistic regression estimation for duration of joblessness (in quarters)

\begin{tabular}{lcccc} 
Hired to: & Any new job & \multicolumn{3}{c}{ A comparable new job } \\
\hline Variable & Coefficient & Std. Err. & Coefficient & Std. Err. \\
\hline Log Job accessibility: 0-20 minutes & $-0.020^{* *}$ & 0.007 & $-0.021 * *$ & 0.007 \\
Log Competing searchers: 0-20 minutes & $0.069 * * *$ & 0.011 & $0.049 * * *$ & 0.012 \\
Female & $0.039 * * *$ & 0.009 & $0.069 * * *$ & 0.009 \\
Black not-Hispanic & $0.082 * * *$ & 0.011 & $0.224 * * *$ & 0.011 \\
Hispanic & $0.160 * * *$ & 0.014 & $0.209 * * *$ & 0.015 \\
Other not-Hispanic & $0.230^{* * *}$ & 0.022 & $0.212 * * *$ & 0.023 \\
Age 20 to 24 & $-0.178^{* * *}$ & 0.013 & $-0.109 * * *$ & 0.013 \\
Age 35 to 44 & $0.147 * * *$ & 0.011 & $0.142 * * *$ & 0.011 \\
Age 45 to 54 & $0.344 * * *$ & 0.012 & $0.337 * * *$ & 0.012 \\
Age 55 to 64 & $0.895 * * *$ & 0.016 & $0.866 * * *$ & 0.017 \\
Married & $-0.068 * * *$ & 0.014 & $-0.110 * * *$ & 0.015 \\
Log Household earnings & $0.172 * * *$ & 0.017 & $0.137 * * *$ & 0.017 \\
Log Total earnings & $0.748 * * *$ & 0.057 & $0.198 * * *$ & 0.055 \\
Log Earnings from lost job & $-1.315 * * *$ & 0.053 & $-0.594 * * *$ & 0.051 \\
Log Earnings, quarter of separation & $0.117 * * *$ & 0.004 & $0.026 * * *$ & 0.004 \\
Travel to lost job <20 minutes & $0.012 * *$ & 0.003 & $0.043 * * *$ & 0.003 \\
Travel to lost job >40 minutes & $-0.153 * * *$ & 0.004 & $-0.055 * * *$ & 0.004 \\
Job tenure at separated job & $0.070 * * *$ & 0.010 & $0.090 * * *$ & 0.010 \\
Count of jobs in last 2 years & -0.005 & 0.011 & -0.012 & 0.012 \\
Separated Industry: Distribution & $-0.328 * * *$ & 0.012 & $-0.348 * * *$ & 0.013 \\
Separated Industry: Professional Serv. & $-0.327 * * *$ & 0.013 & $-0.445 * * *$ & 0.013 \\
Separated Industry: Institutional Serv. & $0.202 * * *$ & 0.015 & 0.024 & 0.015 \\
Separated Industry: Other Services & $-0.491 * * *$ & 0.012 & $-0.545 * * *$ & 0.013 \\
\hline
\end{tabular}

Notes: $* * * / * * *=$ statistically significant at p-values of $0.05 / 0.01 / 0.001$ level. Specifications include metropolitan area, year, and season fixed effects, with robust standard errors reported. Source: Authors' tabulations of Longitudinal Employer-Household Dynamics data matched to Census 2000. 
Table 6. Predicted likelihoods of obtaining a new job

Predictions for change from 10th to 90th percentile

\begin{tabular}{lrrrrrrr} 
A. Until hired to any job & \multicolumn{3}{c}{ Job accessibility } & \multicolumn{3}{c}{ Competing searchers } \\
\hline Quarter hired & Mean & Low & High & Effect & Low & High & Effect \\
\hline Same quarter as separation & $30.6 \%$ & $30.2 \%$ & $31.1 \%$ & $1.0 \%$ & $31.9 \%$ & $29.5 \%$ & $-2.4 \%$ \\
1 quarter after & $20.8 \%$ & $20.7 \%$ & $20.9 \%$ & $0.2 \%$ & $21.0 \%$ & $20.6 \%$ & $-0.4 \%$ \\
2 quarters after & $11.3 \%$ & $11.3 \%$ & $11.3 \%$ & $-0.1 \%$ & $11.2 \%$ & $11.4 \%$ & $0.2 \%$ \\
3 quarters after & $6.8 \%$ & $6.8 \%$ & $6.7 \%$ & $-0.1 \%$ & $6.6 \%$ & $6.9 \%$ & $0.2 \%$ \\
4 quarters after & $4.4 \%$ & $4.4 \%$ & $4.3 \%$ & $-0.1 \%$ & $4.2 \%$ & $4.5 \%$ & $0.2 \%$ \\
Not hired within 4 quarters & $26.1 \%$ & $26.6 \%$ & $25.7 \%$ & $-0.9 \%$ & $25.0 \%$ & $27.2 \%$ & $2.2 \%$ \\
\hline Total & $100.0 \%$ & $100.0 \%$ & $100.0 \%$ & & $100.0 \%$ & $100.0 \%$ & \\
\hline
\end{tabular}

\begin{tabular}{lrrrrrrr} 
& \multicolumn{3}{c}{ Predictions for change from 10th to 90th percentile } \\
\cline { 3 - 8 } B. Until hired to comparable job & & Job accessibility & \multicolumn{3}{c}{ Competing searchers } \\
\hline Quarter hired & Mean & Low & High & Effect & Low & High & Effect \\
\hline Same quarter as separation & $21.2 \%$ & $20.8 \%$ & $21.6 \%$ & $0.8 \%$ & $21.9 \%$ & $20.5 \%$ & $-1.3 \%$ \\
1 quarter after & $16.4 \%$ & $16.2 \%$ & $16.6 \%$ & $0.3 \%$ & $16.7 \%$ & $16.1 \%$ & $-0.5 \%$ \\
2 quarters after & $9.1 \%$ & $9.1 \%$ & $9.1 \%$ & $0.1 \%$ & $9.2 \%$ & $9.1 \%$ & $-0.1 \%$ \\
3 quarters after & $5.8 \%$ & $5.8 \%$ & $5.8 \%$ & $0.0 \%$ & $5.8 \%$ & $5.8 \%$ & $0.0 \%$ \\
4 quarters after & $1.7 \%$ & $1.7 \%$ & $1.7 \%$ & $0.0 \%$ & $1.7 \%$ & $1.7 \%$ & $0.0 \%$ \\
Not hired within 4 quarters & $45.8 \%$ & $46.4 \%$ & $45.2 \%$ & $-1.3 \%$ & $44.8 \%$ & $46.8 \%$ & $2.0 \%$ \\
\hline Total & $100.0 \%$ & $100.0 \%$ & $100.0 \%$ & & $100.0 \%$ & $100.0 \%$ & \\
\hline
\end{tabular}

Notes: Predictions calculated at mean of all other variables, including indicator variables. Where specified as "mean," the prediction is for average levels of the spatial mismatch variables. Where specified as "low" or "high," the predictions are for the $10^{\text {th }}$ or $90^{\text {th }}$ percentile, respectively, of a given spatial mismatch variable.

Source: Authors' tabulations of Longitudinal Employer-Household Dynamics data matched to Census 2000. 
Table 7. Sub-population ordered logistic regression estimation results for duration of joblessness

\begin{tabular}{|c|c|c|c|c|c|}
\hline \multicolumn{2}{|l|}{ Hired to: } & \multicolumn{2}{|l|}{ Any new job } & \multicolumn{2}{|c|}{ A comparable new job } \\
\hline Sample & Variable & Coefficient & Std. Err. & Coefficient & Std. Err. \\
\hline \multirow[t]{2}{*}{ Male } & Log job accessibility & $-0.023 *$ & 0.009 & -0.015 & 0.009 \\
\hline & Log competing searchers & $0.078 * * *$ & 0.016 & $0.054^{* *}$ & 0.016 \\
\hline \multirow[t]{2}{*}{ Female } & Log job accessibility & -0.018 & 0.010 & $-0.030 * *$ & 0.010 \\
\hline & Log competing searchers & $0.069 * * *$ & 0.016 & $0.053 * *$ & 0.017 \\
\hline \multirow[t]{2}{*}{ White } & Log job accessibility & 0.007 & 0.011 & -0.004 & 0.011 \\
\hline & Log competing searchers & 0.017 & 0.017 & 0.010 & 0.017 \\
\hline \multirow[t]{2}{*}{ Black } & Log job accessibility & 0.004 & 0.018 & -0.017 & 0.019 \\
\hline & Log competing searchers & $0.098^{* *}$ & 0.032 & $0.068 *$ & 0.033 \\
\hline \multirow[t]{2}{*}{ Hispanic } & Log job accessibility & $-0.042 * *$ & 0.012 & $-0.036 * *$ & 0.013 \\
\hline & Log competing searchers & $0.166 * * *$ & 0.030 & $0.135^{* * *}$ & 0.031 \\
\hline \multirow[t]{2}{*}{ Age 20 to 34} & Log job accessibility & -0.018 & 0.010 & $-0.022 *$ & 0.010 \\
\hline & Log competing searchers & $0.078 * * *$ & 0.017 & $0.062 * * *$ & 0.017 \\
\hline \multirow[t]{2}{*}{ Age 35 to 54} & Log job accessibility & -0.010 & 0.010 & -0.010 & 0.011 \\
\hline & Log competing searchers & $0.041^{*}$ & 0.017 & 0.019 & 0.018 \\
\hline \multirow[t]{2}{*}{ Age 55 to 64} & Log job accessibility & $-0.050 *$ & 0.021 & $-0.059 *$ & 0.024 \\
\hline & Log competing searchers & $0.142 * * *$ & 0.035 & $0.108^{* *}$ & 0.039 \\
\hline \multirow[t]{2}{*}{ Manufacturing } & Log industry job accessibility & $-0.052 * * *$ & 0.010 & $-0.055 * * *$ & 0.012 \\
\hline & Log industry competing searchers & $0.111 * * *$ & 0.017 & $0.079 * * *$ & 0.019 \\
\hline \multirow[t]{2}{*}{ Distribution } & Log industry job accessibility & -0.017 & 0.016 & -0.027 & 0.017 \\
\hline & Log industry competing searchers & $0.098^{* *}$ & 0.029 & $0.101^{* *}$ & 0.030 \\
\hline \multirow[t]{2}{*}{ Professional } & Log industry job accessibility & $-0.033^{*}$ & 0.013 & $-0.037 * *$ & 0.013 \\
\hline & Log industry competing searchers & 0.034 & 0.025 & 0.006 & 0.025 \\
\hline \multirow[t]{2}{*}{ Institutional } & Log industry job accessibility & -0.003 & 0.019 & 0.004 & 0.020 \\
\hline & Log industry competing searchers & 0.051 & 0.031 & 0.028 & 0.032 \\
\hline \multirow[t]{2}{*}{ Other services } & Log industry job accessibility & -0.008 & 0.014 & -0.009 & 0.014 \\
\hline & Log industry competing searchers & 0.040 & 0.024 & 0.022 & 0.024 \\
\hline
\end{tabular}

Notes: $* / * * / * * *=$ statistically significant at $\mathrm{p}$-values of $0.05 / 0.01 / 0.001$ level. Specifications include all previous control variables (excluding sub-population controls obviously), metropolitan area, year, and season fixed effects, with robust standard errors reported. No subpopulation analysis was done for those reporting as another race and not-Hispanic.

Source: Authors' tabulations of Longitudinal Employer-Household Dynamics data matched to Census 2000. 


\section{References}

Abowd, John, John Haltiwanger, and Julia Lane. 2004. Integrated Longitudinal EmployeeEmployer Data for the United States. American Economic Review v. 94, pp. 224-229.

Abraham, Katharine and Robert Shimer. 2001. "Changes in Unemployment Duration and Labor Force Attachment," Working Paper.

Andersson, Fredrik, Monica Garcia-Perez, John Haltiwanger, Kristin McCue, and Seth Sanders. 2010. "Workplace Concentration of Immigrants," NBER Working Paper No. 16544.

Andersson, Fredrik, Harry Holzer, and Julia Lane. 2004. Moving Up or Moving On: Who Gets Ahead in the Low-Wage Labor Market? Russell Sage Foundation, New York.

Arnott, Richard. 1998. "Economic Theory and the Spatial Mismatch Hypothesis." Urban Studies v. 35 no. 7 , pp. 1171-1185.

Aslund, O., J. Osth, and Y. Zenou. 2010. "How Crucial is Distance to Jobs for Ethnic Minorities? Old Question - Improved Answer." Journal of Economic Geography v. 10, pp. 389422.

Browne, Irene, Cynthia Hewitt, Leann Tigges, and Gary Green. 2001. "Why Does Job Segregation Lead to Wage Inequality among African Americans? Person, Place, Sector, or Skills?" Social Science Research v. 30, pp. 473-495.

Brueckner, Jan K. and Yves Zenou. 2003. "Space and Unemployment: the Labor-Market Effects of Spatial Mismatch.” Journal of Labor Economics v. 21 no. 1, pp. 242-266.

Burdett, Kenneth and Dale T. Mortensen. 1998. "Wage Differentials, Employer Size, and Unemployment.” International Economic Review v. 39 no. 2 (May), pp. 257-253.

Darby, Michael, John Haltiwanger and Mark Plant. 1985. "Unemployment Rate Dynamics and Persistent Unemployment Under Rational Expectations," American Economic Review v. 75 no. 4 (September), pp. 614-37.

Dardia, M. and R.F. Schoeni. 1996. "Wage Losses of Displaced Workers,” Rand Working Paper.

Davis, Steven J., R. Jason Faberman, and John Haltiwanger. 2010. "Labor Market Flows in the Cross Section and Over Time", National Bureau of Economic Research Working Paper, November.

Ellwood, David. 1986. The Spatial Mismatch Hypothesis: Are There Teenage Jobs Missing in the Ghetto? in R. Freeman and H. Holzer (Ed.) The Black Youth Unemployment Crisis, pp. 147185, Chicago: University of Chicago Press. 
Elsby, Michael, Bart Hobijn, and Asyegul Sahin. 2010. "The Labor Market in the Great Recession." Brookings Papers on Economic Activity (Spring), pp. 1-48.

Fisher, Lynn, Henry Pollakowski, and Jeffrey Zabel. 2009. “Amenity-Based Housing Affordability Indexes.” Real Estate Economics v 37 no 4, pp. 705-746.

Glaeser, Edward L. 1996. "Discussion of O'Regan and Quigley's 'Spatial Effects upon Employment Outcomes'.” New England Economic Review (May/June) pp. 58-64.

Gobillon, Laurent, Harris Selod, and Yves Zenou. 2007. "The Mechanisms of Spatial Mismatch.” Laboratoire D’Economie Appliquee (LEA) Working Paper 0701.

Hellerstein, Judith K., David Neumark, and Melissa McInerney. 2008. "Spatial Mismatch or Racial Mismatch?” Journal of Urban Economics v. 64, pp. 464-479.

Holzer, Harry J., Keith Ihlanfeldt, and David L. Sjoquist. 1994. "Work Search and Travel Among White and Black Youth.” Journal of Urban Economics v. 35, pp. 320-345.

Holzer, Harry J., John M. Quigley, and Steven Raphael. 2003. "Public Transit and the Spatial Distribution of Minority Employment: Evidence from a Natural Experiment." Journal of Policy Analysis and Management v. 22 no. 3, pp. 415-441.

Houston, Donald S. 2005. "Methods to Test the Spatial Mismatch Hypothesis." Economic Geography v. 81 no. 4 (October), pp. 407-434.

Iceland, John and Daniel H. Weinberg. 2002. Racial and Ethnic Residential Segregation: 19802000. U.S. Census Bureau Census 2000 Special Report (CENSR-3).

Ihlanfeldt, Keith. 1993. "Intra-Urban Job Accessibility and Hispanic Youth Employment Rates." Journal of Urban Economics vol. 33, pp. 254-271.

Ihlanfeldt, Keith. 2006. A Primer on Spatial Mismatch within Urban Labor Markets, in A Companion to Urban Economics, R.J. Arnott and D.P. McMillen (Eds.), Oxford: Blackwell Publishing, pp. 404-417.

Ihlanfelt, Keith R. and David L. Sjoquist. 1990. "Job Accessibility and Racial Differences in Youth Unemployment Rates.” American Economic Review v. 80 no. 1 (March), pp. 267-76.

Ihlanfelt, Keith R. and David L. Sjoquist. 1998. "The Spatial Mismatch Hypothesis: A Review of Recent Studies and Their Implications for Welfare Reform." Housing Policy Debate v. 9 no. 4 , pp. 849-892.

Jacobson, Louis S, Robert J LaLonde, and Daniel G, Sullivan. 1993. "Earnings Losses of Displaced Workers." American Economic Review v. 83 no. 4, pp. 685-709. 
Lengermann, Paul and Lars Vilhuber. 2002. "Abandoning the sinking ship: The composition of worker flows prior to displacement," LEHD Technical Paper TP-2002-11.

Kain, John F. 1964. The Effects of the Ghetto on the Distribution of Nonwhite Employment in Urban Areas. Washington, DC: National Academy Press.

Kain, John F. 1968. "Housing Segregation, Negro Employment, and Metropolitan Decentralization.” Quarterly Journal of Economics v. 82 no. 1 (February), pp. 32-59.

Kain, John F. 1992. "The Spatial Mismatch Hypothesis: Three Decades Later.” Housing Policy Debate v. 3 no. 2 , pp. 371-460.

Kain, John F. 2004. “A Pioneer's Perspective on the Spatial Mismatch Literature.” Urban Studies v. 41 no. 1 (January), pp. 7-32.

McKinney, Kevin and Las Vilhuber. 2006. "Using linked employer-employee data to investigate the speed of adjustment in downsizing firms," LEHD Technical Paper TP-2006-03.

O'Regan, Katherine M. and John M. Quigley. 1996a. "Spatial Effects upon Employment Outcomes: The case of New Jersey Teenagers." New England Economic Review (May/June) pp. 41-58.

O'Regan, Katherine M. and John M. Quigley. 1996b. "Teenage Employment and the Spatial Isolation of Minority and Poverty Households." Journal of Human Resources v. 31 no. 3 (Summer), pp. 692-702.

Perle, Eugene D., Harald Bauder, and Nancy Beckett. 2002. "Accessibility Measures in Spatial Mismatch Models.” The Professional Geographer v. 54 no. 1, pp. 106-110.

Raphael, Steven. 1998. "Intervening Opportunities, Competing Searchers, and the IntraMetropolitan Flow of Male Youth Labor," Journal of Regional Science v. 38 no. 1, pp. 43-59.

Raphael, Steven, and Michael Stoll. 2001. "Can Boosting Minority Car-Ownership Rates Narrow Inter-Racial Employment Gaps?” Brookings-Wharton Papers on Urban Affairs vol. 2 no. 1, pp. 94-145.

Raphael, Steven, and Michael Stoll. 2002. "Modest Progress: The Narrowing Spatial Mismatch Between Blacks and Jobs in the 1990s.” The Brookings Institution: Washington, DC.

Zax, Jeffrey, and John Kain. 1996. "Moving to the Suburbs: Do Relocating Companies Leave Their Black Employees Behind?” Journal of Labor Economics v. 14, pp. 472-504.

Zenou, Yves. 2009. Urban Labor Economics. Cambridge University Press, Cambridge. 